\title{
GPs challenge seven-day NHS proposal
}

$\mathrm{S}$ even-day access to the National Health Service (NHS) in the United Kingdom is expected to be implemented by 2020 as part of ongoing reforms. Secretary of State for Health Jeremy Hunt reiterated the UK government's motivations in a recent speech in London: to increase access as part of a broader shift toward "patient power" and to reduce "the weekend effect" on patient outcomes and mortality. "A patient-centred system cannot justify mortality rates $15 \%$ higher for those admitted on a Sunday compared to those admitted on a Wednesday."

Criticisms of the seven-day scheme range from challenges of the government's interpretation of the facts to doubts about the practical aspects of implementing the change. The $B M J$ issued a news release stating that its editor had written to Hunt "outlining concerns that he has misrepresented an academic article on deaths of patients admitted to hospitals at weekends." In addition, a spokesperson for the British Medical Association pointed out that any-hour care is already available.

General practitioner (GP) offices currently serve patients at peak times and have on-call numbers for afterhours care. In addition to hospital emergency rooms and the emergency number 999 , there is also a phone number (111) that people can call if they feel unwell so they can be directed to an appropriate medical service.

As for every-day access to GP services, Royal College of General Practitioners Chair Dr. Maureen Baker said in a speech that it was not possible, given that GP surgeries are underfunded and understaffed as it is. The government is living in "cloud cuckoo land" if it expects GP surgeries to open seven days a week, stated Baker.

There are two tracks to the sevenday NHS proposal, one for GPs and one for hospitals. GP offices would open weekday evenings and on weekends,

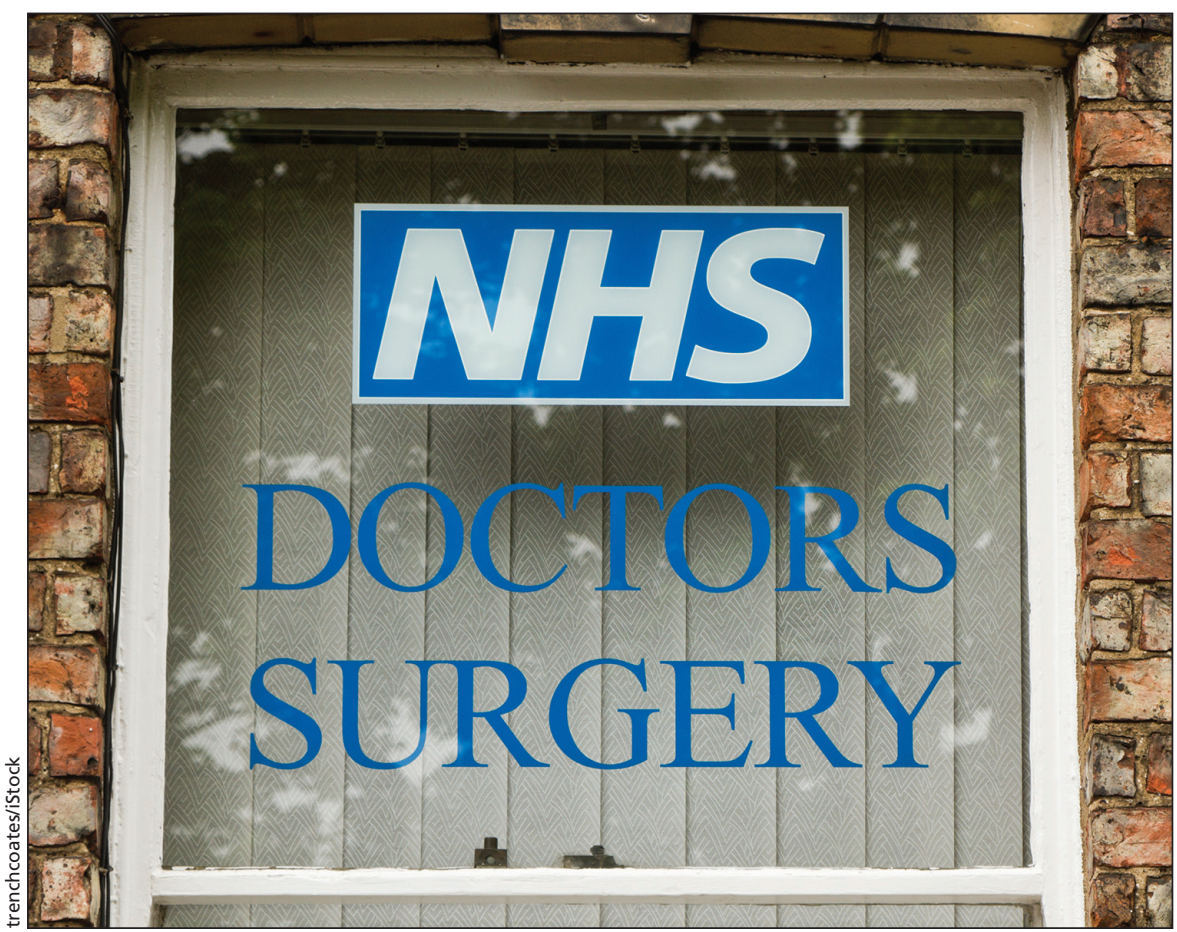

General practitioners in the UK, many with offices that are understaffed and underfunded, question the feasibility of extending hours.

giving patients, in theory, care when they wanted it and reducing their numbers in emergency rooms. Hospitals, meanwhile, would have to provide "the same high-quality, safe hospital care on a Saturday and Sunday as they do on a weekday. This means having enough doctors available to assess and review patients, providing access to important diagnostic tests," according to a government news release.

Is there going to be a cash infusion to pay for extended opening times? The contentious contract on offer to junior doctors suggests the government is trying to get more for less. Baker called for an investment of an extra $£ 750$ million into general practice in $2016 / 17$ for existing services. How much more would be needed for extended hours? We can get an idea of that from the Prime Minister's Challenge Fund, which saw 20 pilot sites distribute $£ 50$ million to 1100 general practices to trial the seven-day scheme.
A recently released report on the Prime Minister's Challenge Fund (now called the GP Access Fund) is already been used by opposing sides to defend their positions. The government has seized on the finding that "there had been a $15 \%$ reduction in minor selfpresenting" emergency department attendances as proof that extended GP services are a success. Critics such as the British Medical Association, however, have focused on the finding that "patient demand for routine appointments on Sundays has been very low" as proof that funding could be better spent elsewhere. As Baker put it: "Seven day access may be a lofty political aspiration but at a time when general practice is already creaking at the seams, we do not think it is a good use of NHS resources to be offering ear syringing on a Sunday teatime." - Debra Martens, London, UK

CMAJ 2016. DOI:10.1503/cmaj.109-5195 